\title{
Increase in the radioresistance of normal skin fibroblasts but not tumor cells by mechanical injury
}

\author{
Zelin Chen ${ }^{1}$, Xin Wang ${ }^{1}$, Taotao Jin ${ }^{1}$, Yu Wang ${ }^{1}$, Christopher S Hong ${ }^{2}$, Li Tan ${ }^{1}$, Tingyu Dai', Liao Wu', Zhengping Zhuang ${ }^{2}$ and \\ Chunmeng Shi ${ }^{*}, 1$
}

The timing of radiation after mechanical injury such as in the case of surgery is considered a clinical challenge because radiation is assumed to impair wound healing. However, the physiological responses and underlying mechanisms of this healing impairment are still unclear. Here, we show that mechanical injury occurring before ionizing radiation decreases radiation-induced cell damage and increases cell repair in normal fibroblasts but not tumor cells in vitro and in vivo. At the molecular level, mechanical injury interrupts focal adhesion complexes and cell-cell cadherin interactions, transducing mechanical signals into intracellular chemical signals via activation of the phosphatidylinositol 3-kinase (PI3K), Akt, and glycogen synthase kinase 3 beta (GSK-3 $\beta$ ) pathways. We show that subsequent nuclear translocation of nuclear factor (erythroid-derived 2)-like 2 (Nrf2) and $\beta$-catenin strengthen the stemness, antioxidant capabilities, and DNA double-strand break repair abilities of fibroblasts, ultimately contributing to increased radioresistance. Our findings demonstrate that mechanical injury to normal fibroblasts enhances radioresistance and may therefore question conventional wisdom surrounding the timing of radiation after surgery.

Cell Death and Disease (2017) 8, e2573; doi:10.1038/cddis.2016.416; published online 2 February 2017

The potential for harmful radiation exposure has increased dramatically with the widespread application of radioisotopes in medicine and radiotherapy for cancer patients and possible threats from nuclear accidents or radiological terrorist attacks. Under such potential exposure scenarios, radiation often occurs in combination with other injuries, especially wound trauma. Previous studies have demonstrated that radiation exposure combined with wound trauma results in a negative synergistic effect that is much more harmful than either insult would produce alone. ${ }^{1,2}$ lonizing irradiation (IR) has long been known to greatly delay skin wound healing, exhibiting impaired inflammatory responses and decreased vascularity and collagen production. ${ }^{3,4,5}$ However, few studies provide a comprehensive understanding of such healing-impaired wounds. To provide more evidence of the physiological mechanisms underlying the effects of radiation on wound healing, we focus on the physiological response to IR combined with mechanical injury to fibroblasts, the main repair cells involved in wound healing. Surprisingly, the results showed that the order of occurrence of radiation and mechanical injury affected the outcome of combined effects such that survivals of fibroblasts improved when mechanical injury occurred prior to IR exposure. However, tumor cells did not show this alleviative combined effect. Further in vitro and in vivo investigation indicated that mechanical injuries decrease IR-induced cell damage and accelerate cell recovery. Mechanical injuries interrupt focal adhesion complexes and cadherin-catenin complexes, which in turn increases the stemness, antioxidant ability, and DNA double-strand breaks
(DSBs) repair by activating the phosphatidylinositol 3-kinase (PI3K)/Akt/glycogen synthase kinase 3 beta (GSK-3 $\beta$ )/ Nuclear factor (erythroid-derived 2)-like 2 (Nrf2) and $\beta$-catenin signaling pathways, finally contributing to increased radioresistance. Our findings might provide investigators or doctors with alternative measures for treating combined injuries involving irradiation and wounds.

\section{Results}

Mechanical injury increases survival of fibroblasts following IR exposure. To explore the combined effects of IR and wound trauma on fibroblasts, we used a mechanical scratch model to mimic wound injury, and cells were exposed to IR of 5 Gy before and after scratching. Cell survival was determined at $72 \mathrm{~h}$ after exposure to three different scenarios: mechanical injury followed by IR (post-wound IR), IR followed by mechanical injury (pre-wound IR), and IR alone without mechanical injury (Figure1a). Fibroblasts in the postwound IR group formed the most colonies, while there were fewer colonies in the pre-wound IR group than in the IR alone group (Figures $1 \mathrm{~b}$ and $\mathrm{c}$ ). Fibroblast colonies in post-wound IR group were also more numerous than in the IR-alone group after exposure to different IR doses (1-7 Gy; Figures 1d and e). However, scratched A549 cells formed fewer colonies than confluent (unscratched) cells following 5 Gy IR (Figure 1f). Cell survival did not differ between scratched and unscratched confluent MG63 cells (Figure 1g).

\footnotetext{
${ }^{1}$ Institute of Combined Injury, State Key Laboratory of Trauma, Burns and Combined Injury, Chongqing Engineering Research Center for Nanomedicine, College of Preventive Medicine, Third Military Medical University, Chongqing 400038, China and ${ }^{2}$ Surgical Neurology Branch, National Institute of Neurological Disorders and Stroke, National Institutes of Health, Bethesda, MD 20892, USA

${ }^{*}$ Corresponding author: C Shi, Institute of Combined Injury, State Key Laboratory of Trauma, Burns and Combined Injury, Chongqing Engineering Research Center for Nanomedicine, College of Preventive Medicine, Third Military Medical University, Chongqing 400038, China. Tel: +860 236 8752280; Fax: +862 368 752009; E-mail: shicm@ sina.com

Received 29.7.16; revised 09.11.16; accepted 11.11.16; Edited by A Oberst
} 


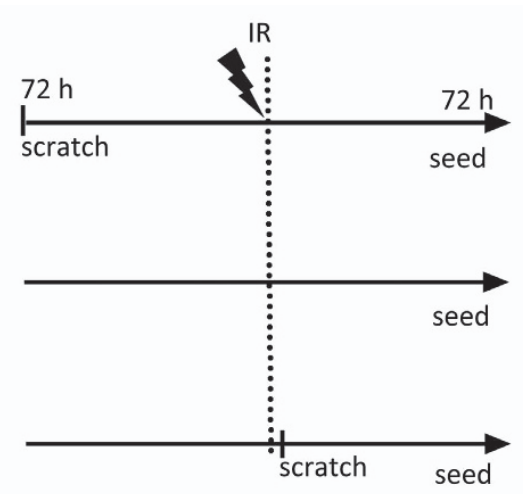

b

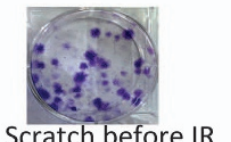

Scratch before IR

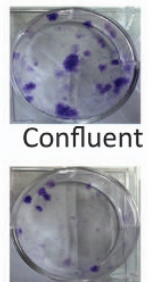

Scratch after IR
C

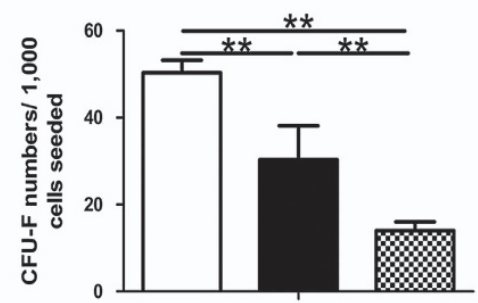

d
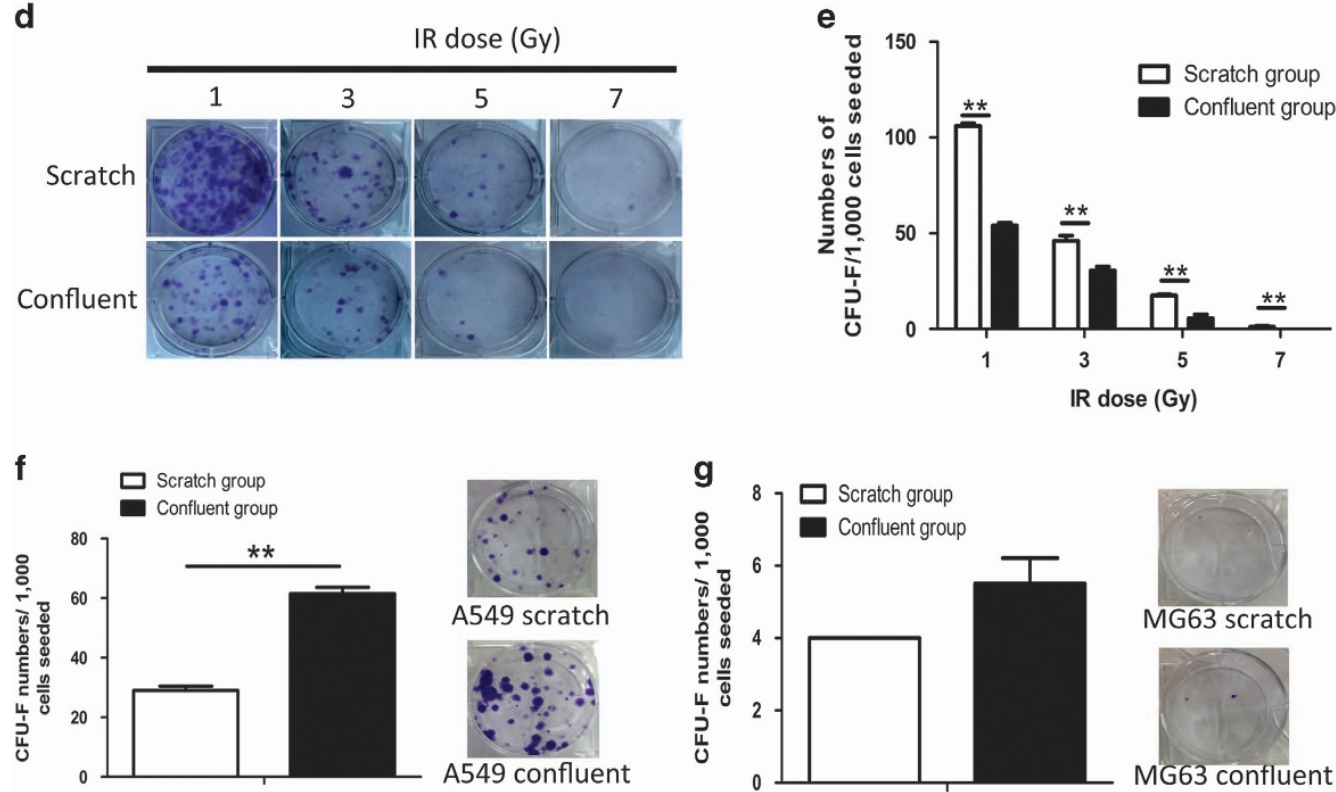

Figure 1 Mechanical injury increases survival of skin fibroblasts after IR. (a) Radiation and mechanical scratch scheme for skin fibroblasts grown to confluence over 7 days. (b) Representative pictures of surviving colonies of skin fibroblasts receiving only radiation, mechanical scratch before radiation, or mechanical scratch after radiation. (c) Quantification of skin fibroblast colonies in groups shown in a. (d) Representative images of surviving skin fibroblast colonies after exposure to radiation alone (1-7 Gy) or mechanical scratch before radiation. (e) Quantification of colonies shown in $\mathbf{d}$. (f) Representative images and quantification of surviving colonies of A549 cells receiving radiation alone (5 Gy) or mechanical scratch before radiation (5 Gy). (g) Representative images and quantification of surviving colonies of MG63 cells receiving radiation alone (5 Gy) or mechanical scratch before radiation (5 Gy). ${ }^{* \star} P<0.01$. $P$-values were calculated using the one-way analysis of variance in $\mathbf{c}$ and the independent-samples $t$-test in $\mathbf{e}-\mathbf{g}$

Furthermore, we compared the colony-forming ability of fibroblasts in vivo receiving wound trauma 3 days before IR to those receiving it immediately after IR. Granulation tissuederived fibroblasts from the mice in the post-wound IR group formed more and larger colonies than those in the pre-wound IR group (Supplementary Figure S1a). These results indicated that mechanical injury occurring prior to IR increased radioresistance in human fibroblasts, while that occurring after IR had the opposite effect. ${ }^{6}$

Mechanical injury decreases IR-induced DNA DSBs in human fibroblasts. DNA DSBs are critical lesions following $\mathrm{IR}^{7} \gamma \mathrm{H} 2 \mathrm{AX}$ is a well-known marker for $\mathrm{DSBs}^{8}$ that disappears as DNA repair mechanisms cease. ${ }^{9,10}$ Fibroblasts achieving confluence over 7 days were mechanically scratched $72 \mathrm{~h}$ before exposure to $5 \mathrm{~Gy} I \mathrm{R}$. $\gamma \mathrm{H} 2 \mathrm{AX}$ foci were rapidly formed in the nuclei of scratched and confluent skin fibroblasts, reaching a maximum level $30 \mathrm{~min}$ after $\mathrm{IR}$ and returning to baseline levels $24 \mathrm{~h}$ after IR (Figure 2a). At each time point before recovery ( $24 \mathrm{~h}$ after IR), the number of $\mathrm{\gamma H} 2 \mathrm{AX}$ foci was significantly lower in the irradiated scratched cells than in the irradiated confluent cells. To exclude the possibility that the decrease in $\mathrm{\gamma H} 2 \mathrm{AX}$ foci formation was simply the result of the mechanical scratch, we compared scratched cells and confluent cells without any IR exposure. Both groups showed low levels of nuclear $\gamma \mathrm{H} 2 \mathrm{AX}$ foci formation; however, scratch injury alone slightly increased $\mathrm{\gamma H} 2 \mathrm{AX}$ foci formation. Western blot analysis also showed lower levels of $\gamma \mathrm{H} 2 \mathrm{AX}$ foci expression and faster decreases in $\mathrm{yH} 2 \mathrm{AX}$ expression in irradiated and scratched fibroblasts. However, in tumor cells (A549 and MG63 cells), scratch wounding prior to irradiation had the opposite effect, increasing $\mathrm{\gamma H} 2 \mathrm{AX}$ expression and 
a
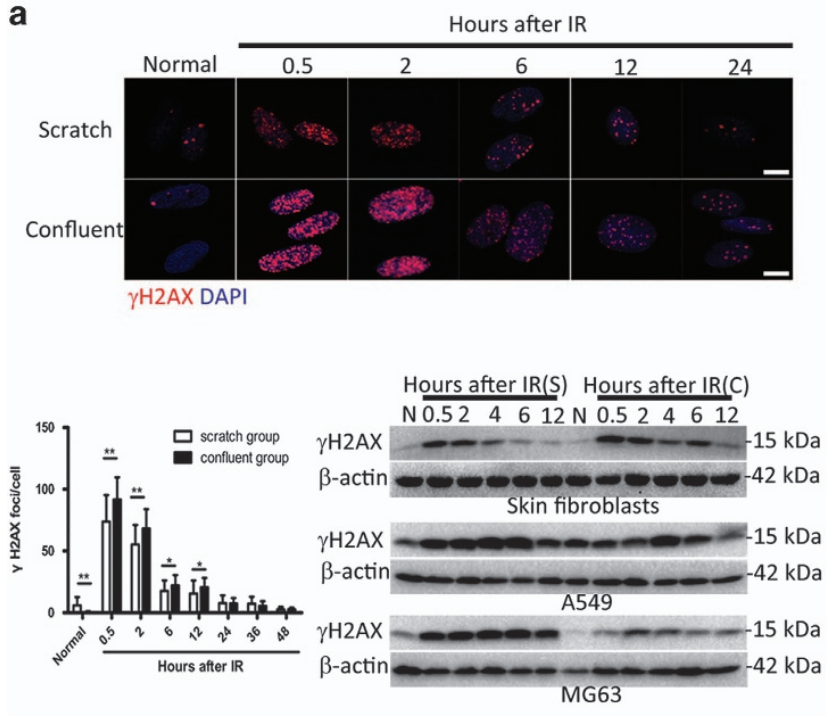

C
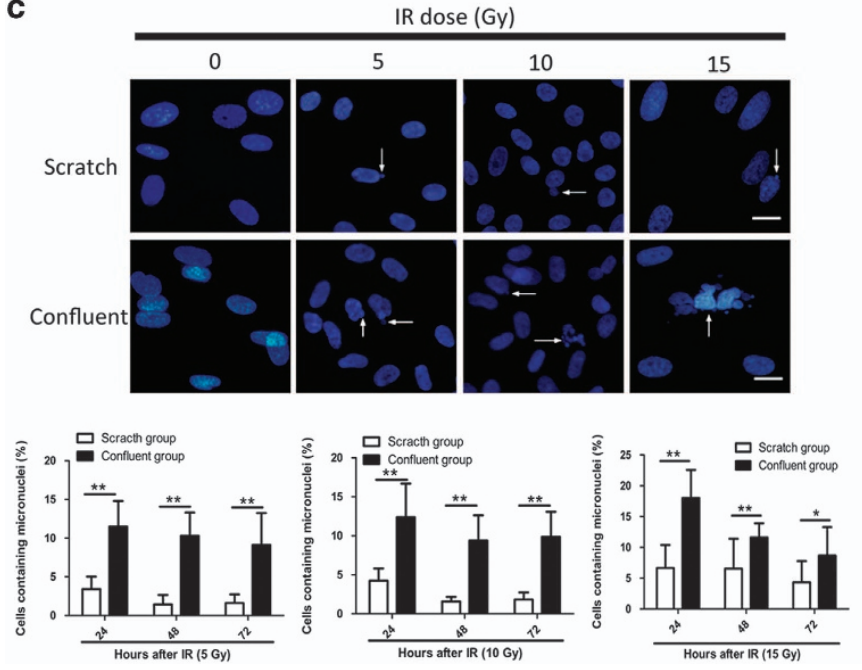

b

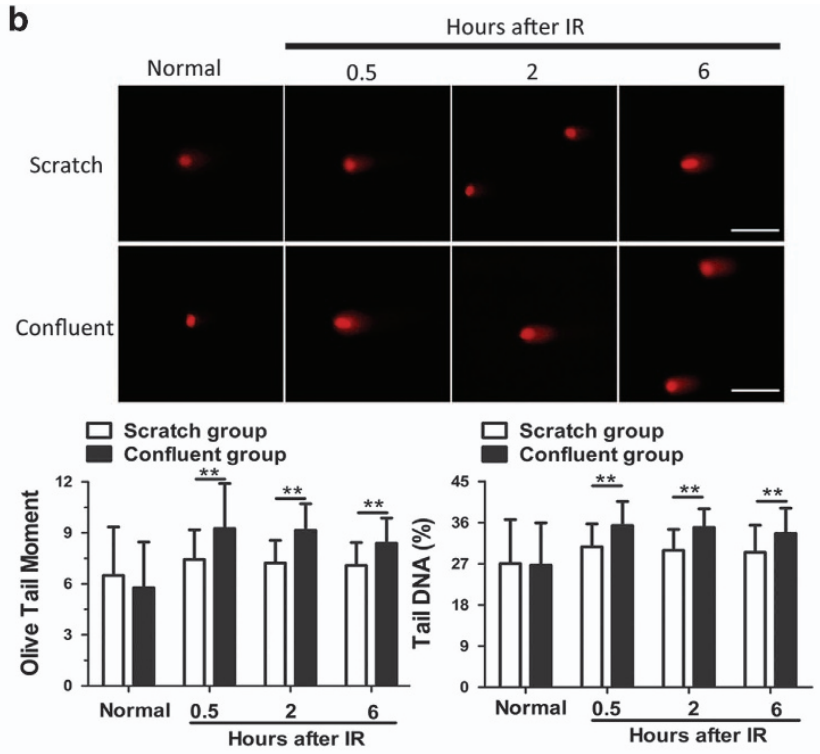

d
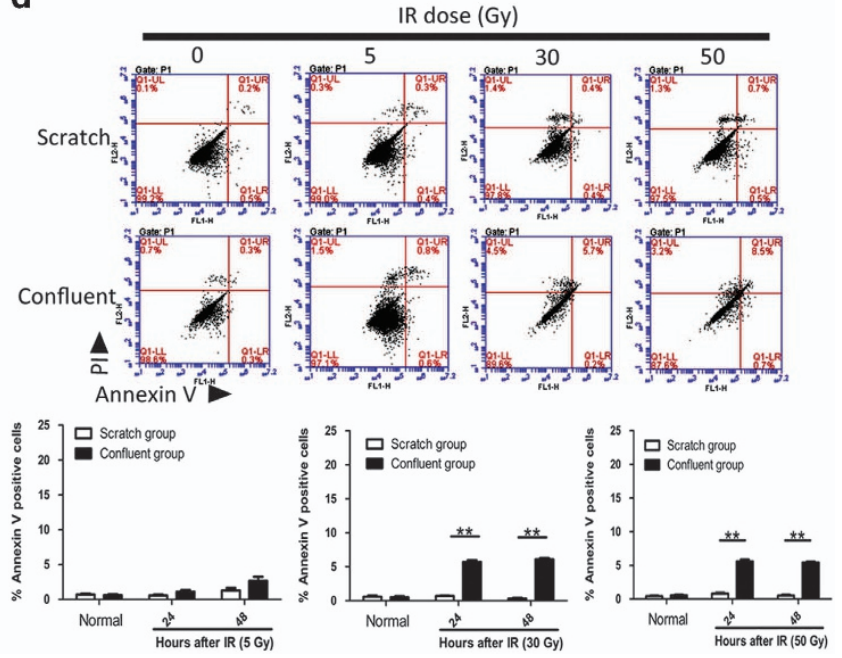

Figure 2 Mechanical injury decreases IR-induced cell damage and apoptosis in skin fibroblasts. (a) Nuclei of mechanically scratched and unscratched confluent skin fibroblasts were co-stained with $\gamma \mathrm{H} 2 \mathrm{AX}$ and 4',6-diamidino-2-phenylindole (DAPI) at the indicated time points following radiation (5 Gy). Scale bars represent $20 \mu \mathrm{m}$. Quantification of $\gamma \mathrm{H} 2 \mathrm{AX}$ foci is also presented. Western blot analysis of $\gamma \mathrm{H} 2 \mathrm{AX}$ expression in mechanically scratched or unscratched confluent cells (skin fibroblasts, A549 cells, and MG63 cells) following radiation (5 Gy) was performed. N, normal; S, scratched; C, confluent. (b) Distribution of comets in mechanically scratched or unscratched confluent skin fibroblasts at indicated time points following radiation (5 Gy). Scale bars represent $100 \mu \mathrm{m}$. The mean olive tail moment and mean tail DNA percentages were also measured. (c) Representative images of micronuclei formation in mechanically scratched or unscratched confluent skin fibroblasts $24 \mathrm{~h}$ following exposure to IR (0-15 Gy). Scale bars represent $20 \mu \mathrm{m}$. Cells containing micronuclei were then quantified. (d) Flow cytometric analysis using the Annexin V-PI double-staining assay of mechanical scratch or unscratched confluent skin fibroblasts $24 \mathrm{~h}$ following exposure to IR (0-50 Gy). ${ }^{* \star} P<0.01 ;{ }^{*} P<0.05$. $P$-values were calculated using the independent-samples $t$-test in a-d

delaying its disappearance (Figure 2a). The presence and repair of DSBs were confirmed by a neutral comet assay that showed significantly shorter olive tail moment and a lower percentage of tail DNA in scratched fibroblasts (Figure $2 b$ ).

Further, we evaluated whether mechanical injury could rescue the deleterious effects of IR in vivo. For these experiments, mice received full-thickness wounds 3 days before radiation to allow fibroblasts at the wound margins to be fully activated. Wounded and non-wounded normal mice were irradiated at a dose of $6 \mathrm{~Gy}$. $\gamma \mathrm{H} 2 \mathrm{AX}$ staining showed that $\gamma \mathrm{H} 2 \mathrm{AX}$-positive fibroblasts showed similar DSBs in normal and wounded skin during the first $2 \mathrm{~h}$ after IR. About $4 \mathrm{~h}$ later, the population of $\gamma \mathrm{H} 2 \mathrm{AX}$-positive cells and the signal intensity were much lower in wounded fibroblasts (Supplementary Figure S1b). In addition, wounded skin in mice received fullthickness wounds 7 and 14 days before radiation showed similar effects compared to normal skin (data not shown).

Mechanical injury decreases IR-induced mitotic catastrophe and apoptosis. Mitotic catastrophe (MC) is another principal form of cell damage induced by IR. ${ }^{11}$ We further analyzed whether or not a mechanical scratch could affect IR-induced MC. At 24, 48, and $72 \mathrm{~h}$ after IR with doses of 5,10 , and 15 Gy, respectively, scratched and confluent 
fibroblasts were stained with DAPI and analyzed to determine the incidence of anaphase chromatid bridges and micronuclei phenotype, the two hallmarks of MC. Anaphase chromatid bridges occurred rarely in both scratched and confluent fibroblasts. However, the micronucleus phenotype was remarkably more frequent in confluent cells than in scratched cells (Figure 2c and Supplementary Figure S2). In addition, IR-induced apoptosis of scratched and confluent fibroblasts was investigated using flow cytometry and calcein-AM/PI staining. Both scratched and confluent fibroblasts showed resistance to $5 \mathrm{~Gy} I \mathrm{R}$. However, with exposure to high doses of IR (30 and $50 \mathrm{~Gy}$ ), apoptosis increased in confluent fibroblasts, but not in scratched fibroblasts (Figure $2 \mathrm{~d}$ and Supplementary Figure S3).

Mechanical injury heightens DSB repair in human fibroblasts. To test the DSB repair mechanisms in scratched fibroblasts following IR, we investigated the expression of ligase IV, DNA-PKcs (NHEJ-related proteins), and Rad51 (an HR-related protein) in scratched and confluent fibroblasts following IR. While the expression of Rad51 was significantly higher in scratched fibroblasts than in confluent fibroblasts (Figures $3 a$ and $b$ ), the expression of DNA-PKcs and ligase IV did not differ significantly (Figure $3 b$ ). We also compared the expression of ligase IV, DNA-PKcs, and Rad51 in nonirradiated scratched cells and confluent cells and found that Rad51 was upregulated following mechanical injury (Figures $3 a$ and $b$ ). These results indicated that mechanical injury enhanced the HR repair of fibroblasts. However, in tumor cells, the increase in Rad51 expression was not as notable in scratched cells as it was in fibroblasts (Figure $3 c$ ).

Mechanical injury accelerates human fibroblasts recovery from IR-induced cell cycle arrest. The increases in cell survival and colony size after IR in scratched fibroblasts suggested that mechanical injury was affecting the activation of DNA damage checkpoints. Consistent with previous studies, ${ }^{12}$ most confluent fibroblasts remained in the G1 phase under normal conditions. After reseeding, they quickly entered the $S$ phase, reaching a peak $24 \mathrm{~h}$ later, and then entered into G2/M phase a subsequent $12 \mathrm{~h}$ later. Altogether, the full cell cycle in human fibroblasts took $36 \mathrm{~h}$ (Figure $3 \mathrm{~d}$ a

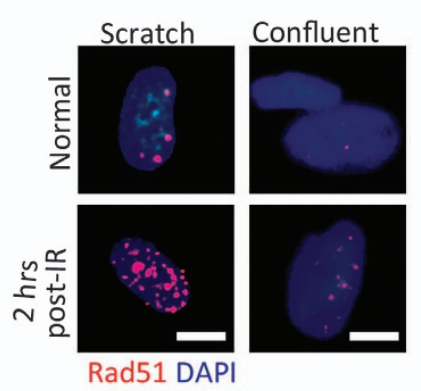

C

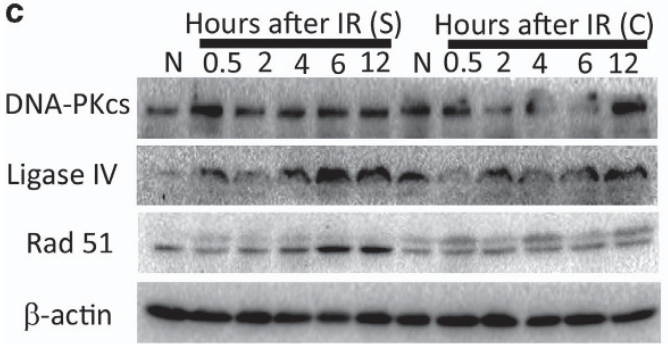

A549

b

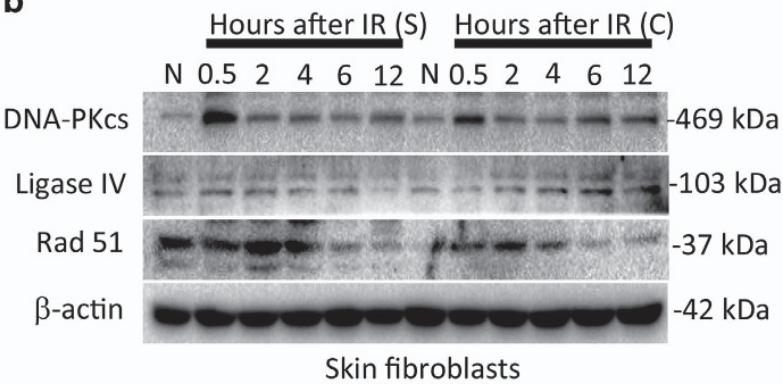

Hours after IR (S) Hours after IR (C) $\mathrm{N} \begin{array}{lllllllllll}0.5 & 2 & 4 & 6 & 12 & \mathrm{~N} & 0.5 & 2 & 4 & 6 & 12\end{array}$

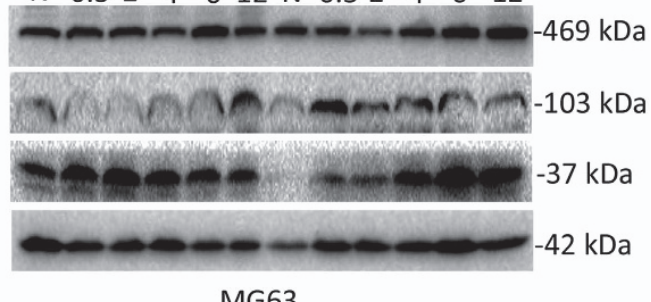

MG63
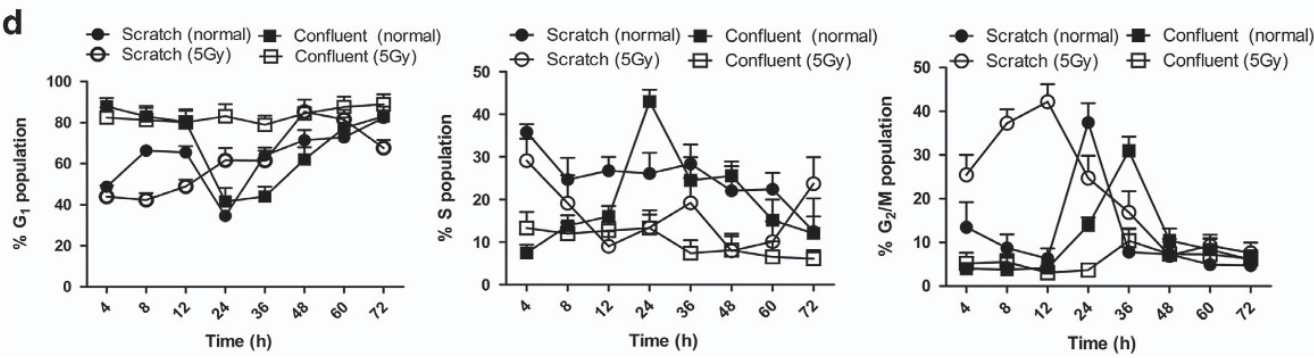

Figure 3 Mechanical injury increases HR repair and accelerates cell cycle arrest recovery of skin fibroblasts. (a) Nuclei of mechanically scratched and unscratched confluent skin fibroblasts were co-stained with Rad51 and DAPI at indicated time points following radiation (5 Gy). Scale bars represent $20 \mu \mathrm{m}$. (b) Western blot analysis of DNA-PKcs, ligase IV, and Rad51 expression in mechanically scratched and unscratched confluent skin fibroblasts following radiation (5 Gy). N, normal; S, scratch; C, confluent. (c) Same as in b, but cells are A549 and MG63 cells. (d) Average fraction (\%) of mechanically scratched and unscratched confluent skin fibroblasts in G1, S, and G2/M phase at indicated time points following radiation ( 0 or 5 Gy) 
a

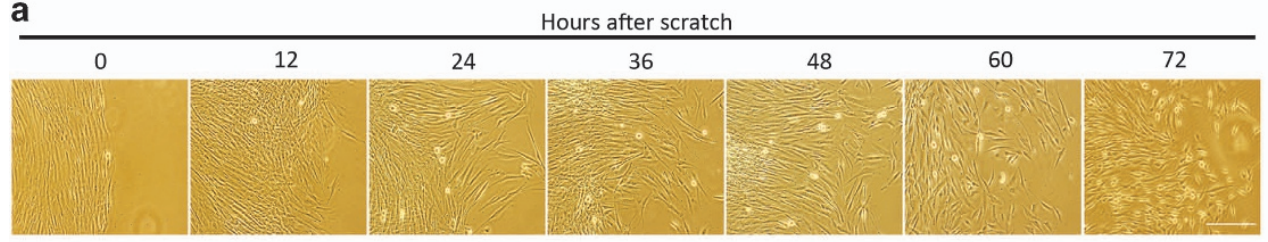

b

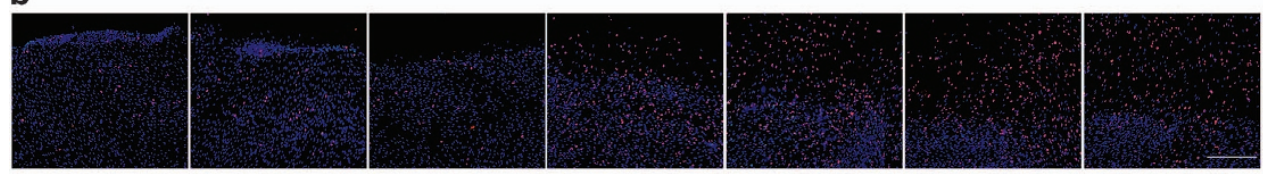

Ki67 DAPI

c

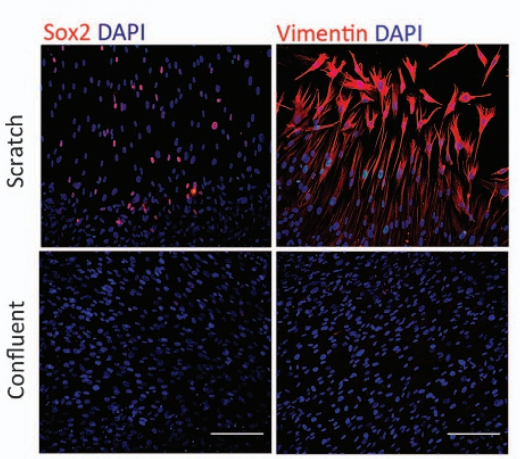

d

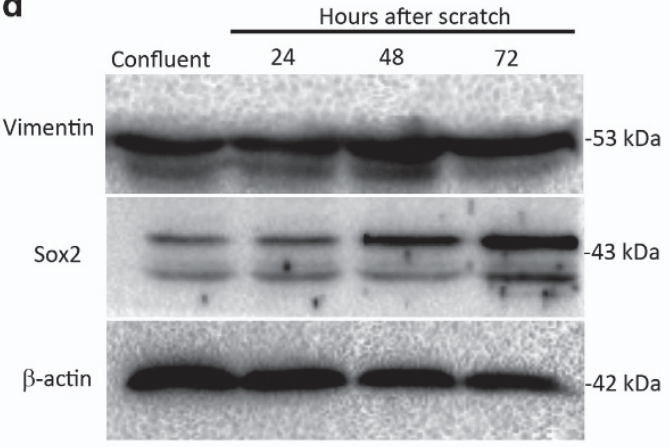

e

f

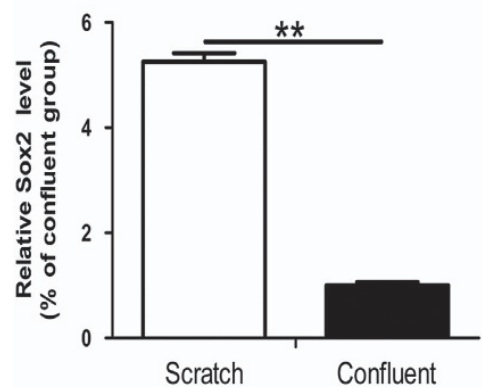

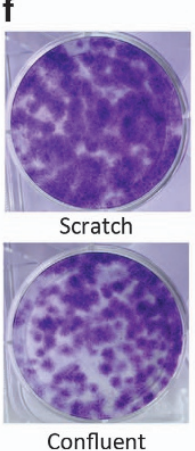

g

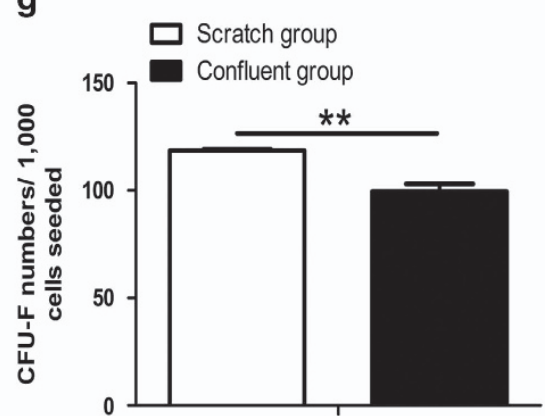

Figure 4 Characterization of changes in skin fibroblasts following mechanical injury. (a) Representative images of skin fibroblasts in wound margins following mechanical scratch. Scales bars represent $500 \mu \mathrm{m}$. (b) Immunofluorescence staining for Ki67 demonstrating activation of skin fibroblasts following mechanical scratch. Cell nuclei are counterstained with DAPI. Scales bars represent $500 \mu \mathrm{m}$. (c) Immunofluorescence staining for Sox2 and vimentin in skin fibroblasts at the scratch edge $72 \mathrm{~h}$ after mechanical scratch. Cell nuclei are counterstained with DAPI. Scales bars represent $200 \mu \mathrm{m}$. (d) Western blot analysis of Sox2 and vimentin expression at indicated time points in skin fibroblasts following mechanical scratch. (e) Real-time PCR analysis of Sox2 expression in skin fibroblasts $72 \mathrm{~h}$ after mechanical scratch. (f) Colony formation assay of skin fibroblasts $72 \mathrm{~h}$ after mechanical scratch. $(\mathbf{g})$ Quantification of colonies in f. ${ }^{* *} P<0.01$. $P$-values were calculated using the independent-samples $t$-test in $\mathbf{e}$ and $\mathbf{g}$

and Supplementary Table S1). We observed that after exposure to 5 Gy IR, confluent fibroblasts arrested mainly at the $\mathrm{G} 1 / \mathrm{S}$ phase with recovery occurring $24 \mathrm{~h}$ after IR, while scratched fibroblast arrested mainly at the G2/M phase with recovery occurring $12 \mathrm{~h}$ after IR (Figure $3 \mathrm{~d}$ and Supplementary Table S1). These results indicated that mechanical injury accelerated the recovery of fibroblasts from cell cycle arrest induced by IR.

Mechanical injury induces the stemness phenotype change in human fibroblasts. To determine how mechanical injury could increase the radioresistance of human fibroblasts, we further investigated cell phenotype changes after wounding. After scratching, fibroblasts quickly migrated into the wound within $1 \mathrm{~h} .24 \mathrm{~h}$ later, the cells at the wound margin developed a small, round phenotype, which peaked in prevalence $72 \mathrm{~h}$ later (Figure $4 \mathrm{a}$ ). In addition, Ki67 staining showed that the proliferation of fibroblasts in the wound margin was completely activated $36 \mathrm{~h}$ after scratching (Figure 4b). However, in tumor cells, proliferation was only partially inhibited by confluence, and activation of proliferation occurred sooner $(12 \mathrm{~h})$ after mechanical injury (Supplementary Figure S4). Further experiments revealed that the activation of proliferation in fibroblasts was not dependent on wound size, either in vitro or in vivo (Supplementary Figures S5 and S6).

Molecular markers of fibroblast activation were analyzed to further understand phenotype changes in fibroblasts in 
response to wounding. Given recent studies have associated the stemness phenotype with radioresistance in some stem cell types, ${ }^{13}$ markers of stemness in fibroblasts were specifically investigated. Expression of the pluripotent stem cell marker sex-determining region Y-box 2 (Sox2) and the mesenchymal cell marker vimentin was upregulated at wound margins (Figure 4c). Other tested markers, including octamerbinding transcription factor-4 (Oct4), Nanog, collagen I, chemokine receptor-4 (CXCR4), fibronectin, and $a$-smooth muscle actin ( $a$-SMA), were unchanged after scratching (Supplementary Figure S7). We then determined the spatial and temporal changes in Sox2 and vimentin expression. Vimentin was strongly expressed in migratory cells in the cavity of the wound $12 \mathrm{~h}$ after scratching and returned to normal levels after the wound healed. Expression of Sox2 began to increase at $48 \mathrm{~h}$ after scratching and reached a peak at $72 \mathrm{~h}$ (Figures $4 \mathrm{~d}$ and e). The expression of Sox2 and vimentin increased in nearly all fibroblasts at wound margins (Supplementary Fig. S8a). Nearly all cells strongly expressing Ki67 stained with high intensity for Sox2 (Supplementary Figure S8b), indicating that Sox2 might be associated with the proliferation of fibroblasts in response to injury.

Mechanical injury induces changes in the transcriptional state of human fibroblasts. To further explore enhanced radioresistance induced by mechanical injury, gene expression profiling coupled with bioinformatic analyses were performed and revealed that the focal adhesion pathway, TGF- $\beta$ signaling pathway, and PI3K-Akt signaling pathway were the three most differentially modulated canonical pathways, following mechanical scratch wounding (Figure 5a). There was significant upregulation of genes involved in the cell cycle and activation of proliferation (Figure 5b), consistent with previous data demonstrating high levels of Ki67 expression in response to mechanical injury. The expression of cell adhesion-associated genes also changed greatly following mechanical injury (Figure $5 c$ ), suggesting that elements of the cell membrane responsible for cell adhesion and communication likely play an important role in the sensing of mechanical injury. In addition, our results were consistent with those of previous studies ${ }^{14-16}$ showing that the transforming growth factor- $\beta$ (TGF- $\beta$ ) signaling pathway is intimately involved in wound healing. Transcriptome analysis also demonstrated significantly increased expression of cytoskeleton molecules (Figure 5d), consistent with observations of fibroblast migration from the wound margins directly into the wound cavity after mechanical injury. Furthermore, gene expression of DNA DSB repair-related proteins, particularly the HR system components such as Rad51, XRCC2, and BRCA2, were also upregulated following scratch wounding (Figure 5e). However, expression of anti-apoptotic genes such as $b c / 2$ or $b c /-x l$ showed no significant changes. Taken together, these transcriptional changes provided further evidence at the genomic level of enhanced radioresistance in fibroblasts after mechanical injury.

PI3K/Akt pathway activation involves fibroblast-sensing of mechanical injury. The transcriptional expression data showed that both the focal adhesion and PI3K/Akt pathways were activated following mechanical injury. Previous studies have shown that focal adhesion complexes sense mechanical signals, activating inner focal adhesion kinase (FAK) through focal adhesion complexes ${ }^{17,18,19}$ that in turn activate the PI3K/Akt pathway. ${ }^{20,21}$ The PI3K/Akt pathway is involved in a range of biological processes, including cell survival, proliferation, migration, and stem cell self-renewal. ${ }^{22}$ To explore the role of the PI3K/Akt pathway in fibroblast radioresistance following mechanical injury, we investigated the expression of total Akt and activated serine 473 (ser-473) phosphorylated Akt following mechanical wounding. Ser-473phosphorylated Akt increased $2 \mathrm{~h}$ after scratching (Figure 6a). GSK-3 $\beta$, a serine/threonine kinase involved in the sensing of mechanical signals, ${ }^{23,24,25}$ is inactivated by phosphorylation of Serine-9 (ser-9). Our data also showed that the expression of ser- 9 phosphorylated GSK-3 $\beta$ increased at the same time as upregulation of ser-473 phosphorylated Akt (Figure 6a). The expression of $\beta$-catenin and Nrf2, two downstream proteins of GSK-3 $\beta,{ }^{26,27}$ increased with the inactivation of GSK-3 $\beta$ following mechanical injury (Figure 6b). The administration of LY294002, a PI3K inhibitor, decreased the expression of ser-473-phosphorylated Akt and ser-9-phosphorylated GSK-3 $\beta$ and abolished scratchinduced upregulation of $\beta$-catenin and Nrf2, further verifying that the PI3K/Akt pathway was being activated by mechanical injury. Inactivation of GSK-3 $\beta$ by the inhibitor SB216763 also significantly increased the expression of $\beta$-catenin and Nrf2 in confluent fibroblasts (Figure $6 \mathrm{~b}$ ). These results indicated that mechanical injury upregulates the expression of $\beta$-catenin and Nrf2, two critical transcription factors involved in cell proliferation and survival, by activating the PI3K/Akt pathway.

\section{$\beta$-catenin initiates conversion to the stemness phenotype in human fibroblasts following mechanical injury.} According to our gene expression data, the focal adhesion pathway is primarily responsible for sensing mechanical injury. In addition to focal adhesion complexes, cadherincadherin interactions between cells are also critical sensors of mechanical injury. $\beta$-catenin is a ubiquitous transcription factor located on the inner surface of cadherins that can be activated at the cell membrane, resulting in its nuclear translocation and the transcription of several genes related to proliferation and stemness. ${ }^{28}$ Confirming our earlier data showing increased transcriptional levels of $\beta$-catenin in scratched fibroblasts, immunofluorescence staining demonstrated that both total $\beta$-catenin and activated (phosphorylated at Ser-675) $\beta$-catenin levels were higher in fibroblasts at the margins of the wound cavity (Figure 6c). Western blot analysis also showed that the expression of total and activated $\beta$-catenin was elevated $2 \mathrm{~h}$ following scratching (Figure $6 \mathrm{~d}$ ). To further elucidate the role of $\beta$-catenin in the radioresistance of fibroblasts, siRNA knockdown of $\beta$-catenin was performed (Supplementary Figure S9). Knockdown of $\beta$-catenin resulted in minimally decreased expression of vimentin following scratching (Supplementary Figure S10), but significantly decreased the expression of Sox2 (Figures $6 e$ and $f$ ). Furthermore, the survival of fibroblasts after IR was decreased by $\beta$-catenin knockdown (Figures $6 \mathrm{~g}$ and $\mathrm{h}$ ). These results indicated that $\beta$-catenin plays a critical role in the conversion to a stemness phenotype in fibroblasts 
a

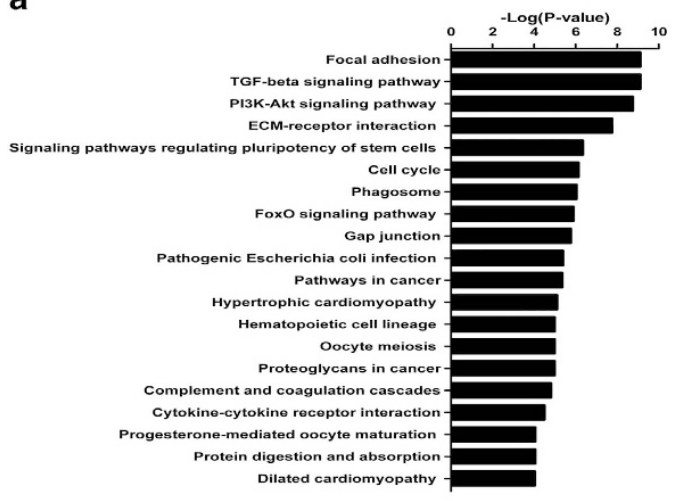

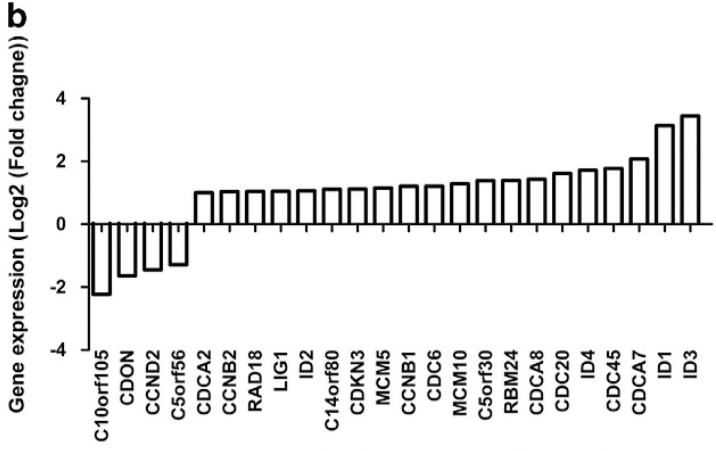

Gene expression of cell cycle associated molecules

C

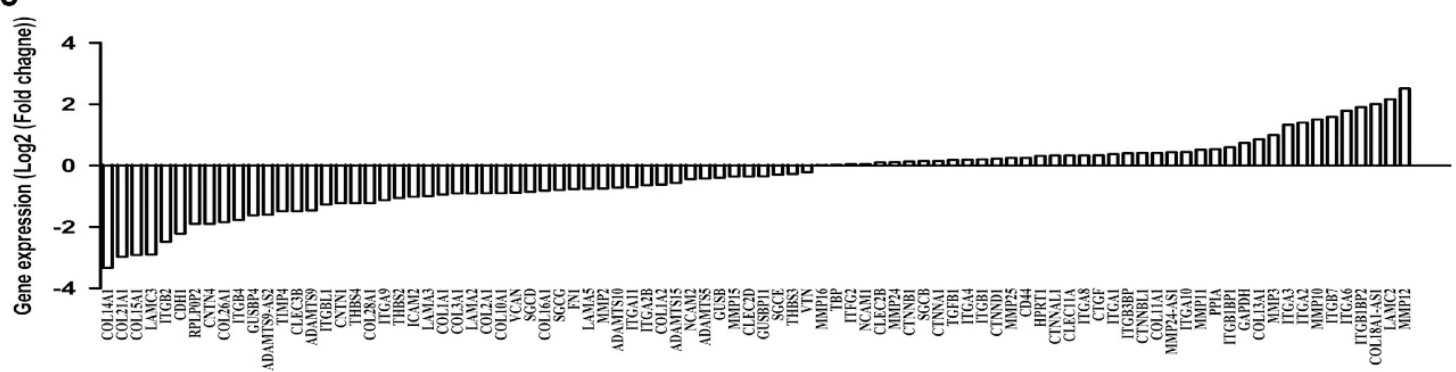

Gene expression of cellular adhesion associated molecules

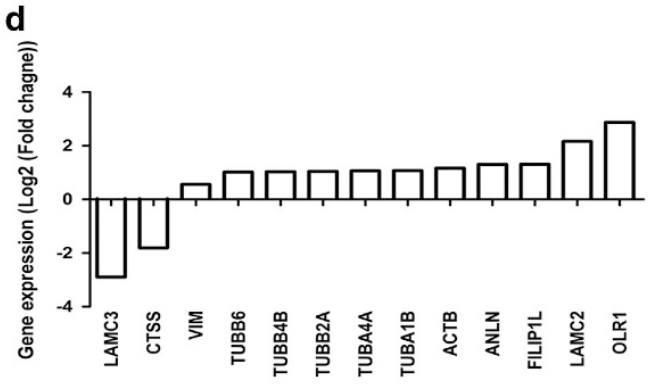

Gene expression of cytoskeleton associated molecules

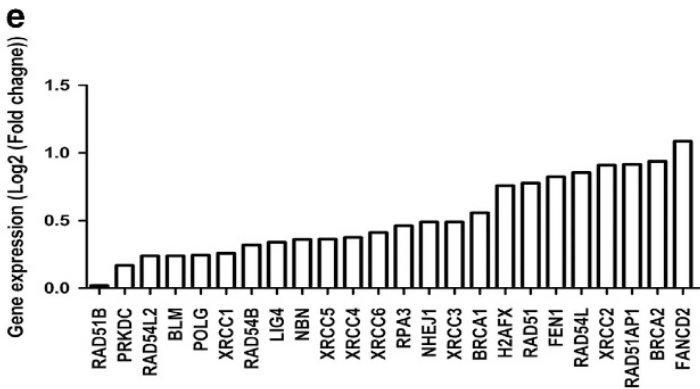

Gene expression of DNA repair associated molecules

Figure 5 Transcriptional changes in skin fibroblasts following mechanical injury. Skin fibroblast monolayers were grown to confluence over 7 days and scratched. Total RNA of mechanically scratched and unscratched confluent skin fibroblasts were harvested $72 \mathrm{~h}$ later. Expression profiles were analyzed. (a) KEGG pathway analyses of transcriptomes of mechanically scratched and unscratched confluent skin fibroblasts. (b-e) Altered expression of genes encoding proteins associated with the cell cycle, cellular adhesion, cytoskeleton, and DNA repair was observed

following mechanical injury and contributes to their radioresistance.

Nrf2 mediates increased antioxidant capability and DSB repair in human fibroblasts following mechanical injury. Reactive oxygen species (ROS) are critical mediators of IR-induced cell damage. Our observation that $\gamma \mathrm{H} 2 \mathrm{AX}$ foci formation decreased and resolved more quickly in response to mechanical injury suggested an increase in the antioxidant activity and DNA repair in fibroblasts following mechanical injury. Endogenous ROS levels were observed to decrease following mechanical injury (Figure 7a). We tested the expression of several well-known antioxidant enzymes, including superoxide dismutase1 (SOD1), SOD2, catalase, and glutathione peroxidase 1 (GPX-1), and found that SOD1 expression increased significantly following scratching (Figure 7b). The upregulation of SOD1 in scratched fibroblasts did not occur immediately after scratch injury but $36 \mathrm{~h}$ later, demonstrating that the upregulation of SOD1 is a secondary molecular event triggered by mechanical injury. Previous studies have indicated that Nrf2 is a key regulator of antioxidant gene expression. ${ }^{29}$ The above data have indicated that the increases of Nrf2 in fibroblasts resulted from the inactivation of GSK-3 $\beta$. Immunofluorescence staining also showed enhanced Nrf2 expression in fibroblasts at the margins of the wound cavity (Figure 7c), and western blot analysis revealed an increase in both total Nrf2 and activated (phosphorylated at serine 40) Nrf2 proteins (Figure 7d). However, expression of antioxidant proteins did not increase following mechanical injury in A549 and MG63 tumor cells 
a

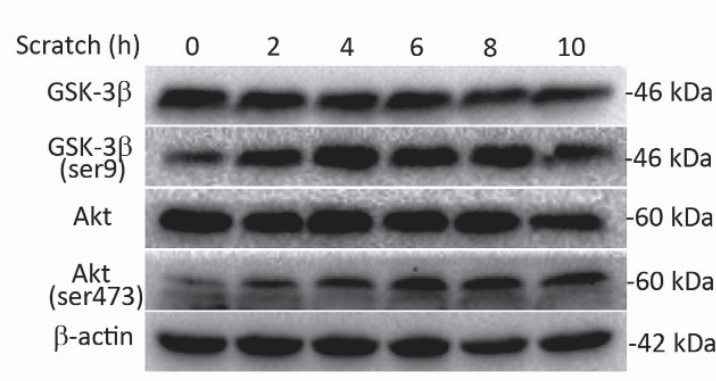

C

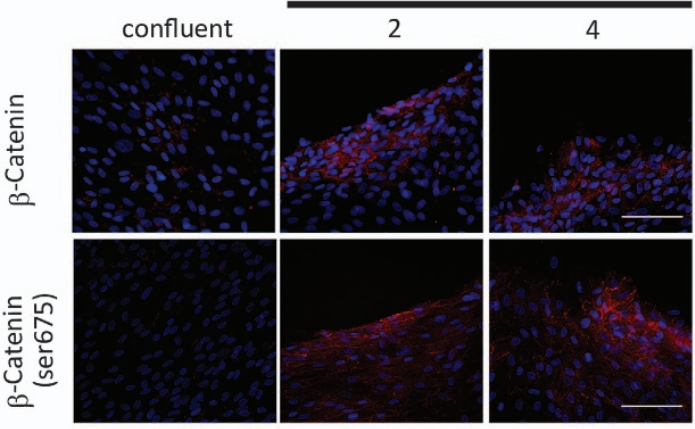

e

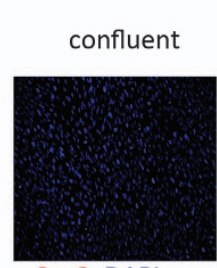

Sox2 DAPI

g

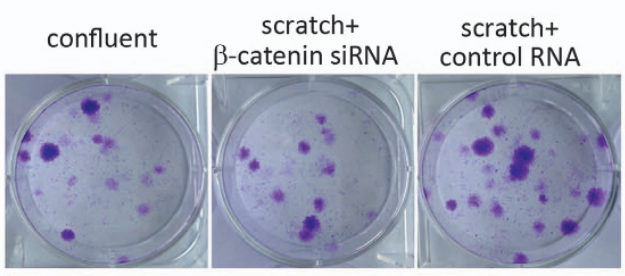

b

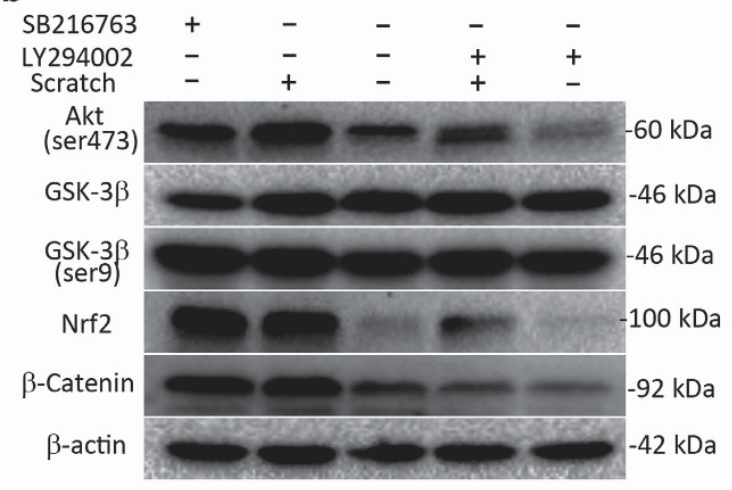

d

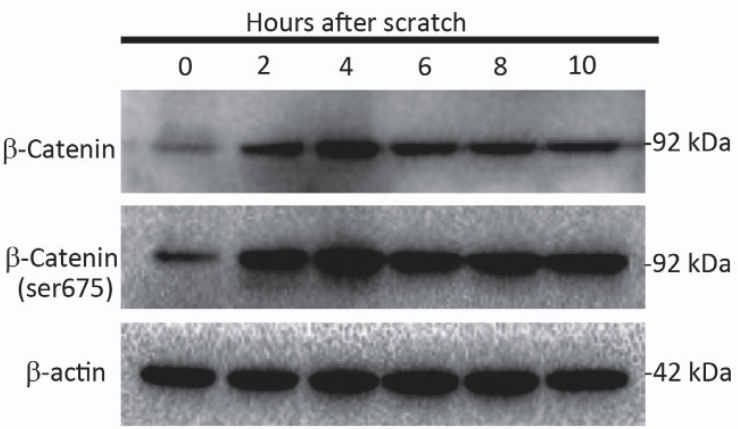

f
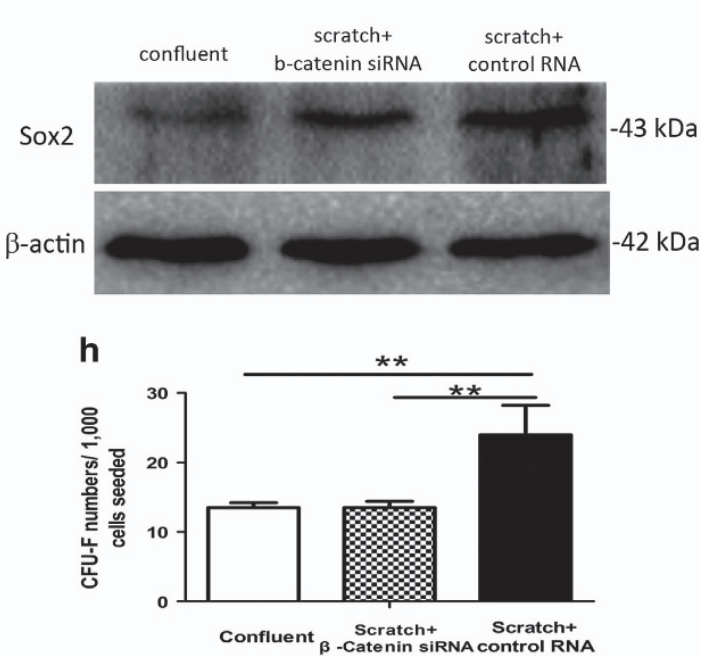

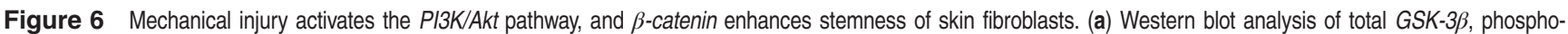
GSK-3 $\beta$ at Ser-9, and upstream Akt (total and phosphorylated at Ser-473) in skin fibroblasts following mechanical scratch. (b) Western blot analysis of skin fibroblasts treated with LY294002 and SB216763. (c) Immunofluorescence staining of total $\beta$-catenin and phospho- $\beta$-catenin at Ser-675 at 2 and $4 \mathrm{~h}$ post scratch. Scale bars represent $200 \mu \mathrm{m}$. (d) Western blot analysis of total $\beta$-catenin and phospho- $\beta$-catenin at Ser-675 at various time points following mechanical scratch. (e and f) Immunofluorescence staining and western blot analysis of Sox2, indicating a decrease in expression following $\beta$-catenin knockdown. (g) Clonogenic survival assay of mechanically scratched and unscratched confluent skin fibroblasts following knockdown of $\beta$-catenin when exposing to radiation of $5 \mathrm{~Gy}$. (h) Quantification of colonies in $\mathbf{g}$. ${ }^{*} P<0.01$. $P$-values were calculated using the one-way analysis of variance

(Supplementary Figure S11). In further support of Nrf2mediated regulation of antioxidant gene expression, siRNA knockdown of Nrf2 (Supplementary Figure S9b) diminished mechanical injury-induced upregulation of SOD1 (Figure 7e). Rad51 expression was also diminished by knockdown of Nrf2, while ligase IV and DNA-PKcs were not affected
(Figure 7e). Fibroblast survival following IR was also significantly decreased by Nrf2 knockdown (Figure 7f). Taken together, these findings indicated that Nrf2 is upregulated via the PI3K/Akt pathway following mechanical injury, which in turn increases cellular antioxidant capability and DNA DSB repair by upregulating SOD1 and Rad51 expression, 
a

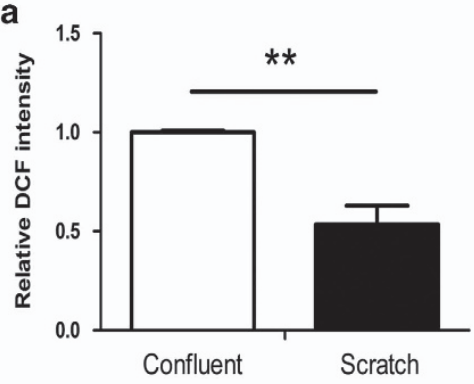

C

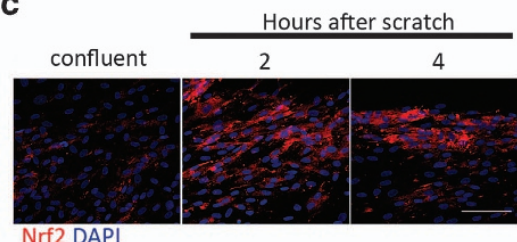

e
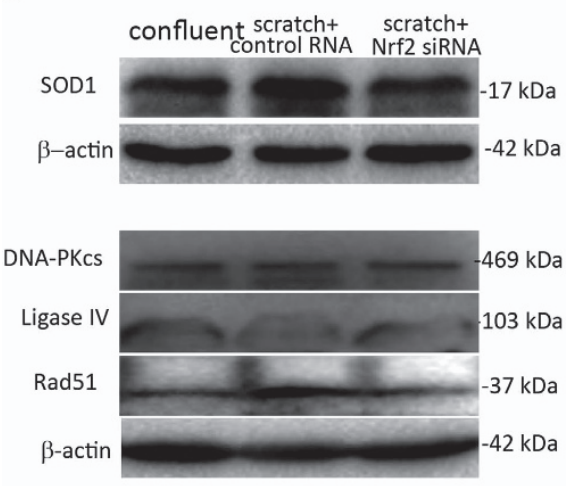

b

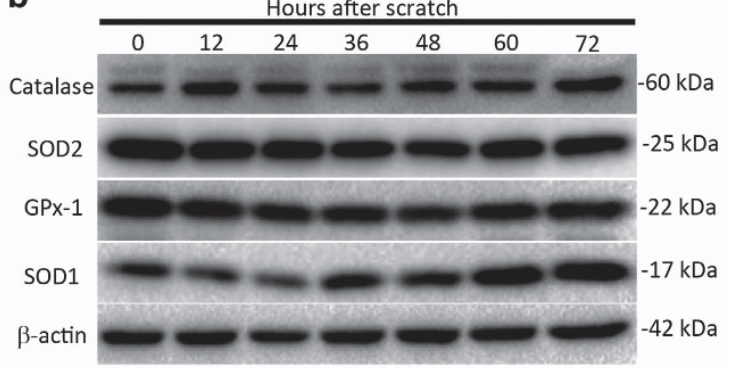

d

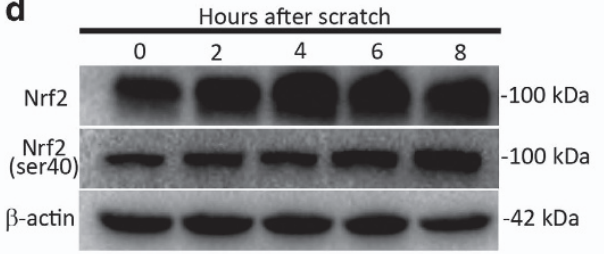

f

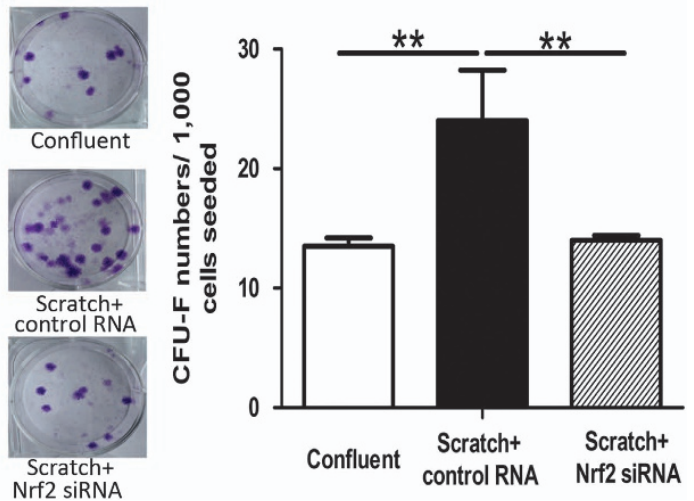

Figure 7 Nrf2 mediates mechanical injury-induced enhancement of antioxidant ability and DSB repair in skin fibroblasts. (a) DCFH-DA flow cytometric analysis of endogenous ROS levels in skin fibroblasts $72 \mathrm{~h}$ following mechanical scratch. (b) Western blot analysis of antioxidant proteins in skin fibroblasts at indicated time points following mechanical scratch. (c) Immunofluorescence staining for total Nif2 at 2 and $4 \mathrm{~h}$ post scratch. Scales bars represent $200 \mu \mathrm{m}$. (d) Western blot analysis of total Nrf2 and phosphoNrf2 at Ser-40 in skin fibroblasts following mechanical scratch. (e) Western blot analysis of SOD1 and DNA repair-related proteins following knockdown of Nrf2. (f) Post-radiation clonogenic survival assay of mechanically scratched and unscratched confluent skin fibroblasts following knockdown of $N$ rf2. ${ }^{* *} P<0.01$. $P$-values were calculated using the independent-samples $t$-test in a and the one-way analysis of variance in $f$

respectively. These changes collectively contribute to increased radioresistance in fibroblasts after mechanical injury.

\section{Discussion}

Using complementary cellular, molecular, and genomic approaches, we have discovered that mechanical injury increase the radioresistance of skin fibroblasts by increasing the stemness, antioxidant capability, and mechanisms of DNA DSB repair (Figure 8). Following mechanical injury, cadherincatenin complexes are interrupted, and $\beta$-catenin is activated at the membrane. ${ }^{30}$ In addition, focal adhesion complexes can sense mechanical signals that activate the inner FAK, ${ }^{17,18,19}$ which in turn activates the PI3K/Akt pathway. ${ }^{20,21}$ GSK-3 $\beta$, a serine/threonine kinase involved in a diverse range of signaling pathways, mediates crosstalk between the PI3K/ Akt and $\beta$-catenin pathways after mechanical injury. Although previous studies have shown that GSK- $3 \beta$ can mediate $\beta$-catenin ${ }^{23,31}$ or $\mathrm{Nrf} 2,{ }^{27}$ the regulation of both $\mathrm{Nrf2}$ and $\beta$-catenin at the same time by GSK-3 $\beta$ in response to a single stimulation factor has not been reported until now.

The radioresistance of stem cells has received much recent attention. ${ }^{13,32}$ Upon mechanical injury, skin fibroblasts change to a relatively primitive differentiation state via a $\beta$-catenindependent pathway. Other studies have also reported that scratch injury or conditioned culture medium from scratchinsulted astrocytes induces de-differentiation of astrocytes into a neural progenitor phenotype. ${ }^{30,33}$ In a previous study, we demonstrated that wound trauma-mediated stemness phenotype changes in mouse skin fibroblasts in vivo. ${ }^{34}$ In this study, we observed that the change in stemness phenotype increased the radioresistance of human skin fibroblasts. Similarly, it has been shown that inducing astrocyte differentiation into neural progenitor phenotypes also contributes to increased radioresistance. ${ }^{35}$ In contrast, mesenchymal stem cells, induced to differentiate, exhibited sharply prolonged DNA DSBs and increased cell death after IR, even during the 


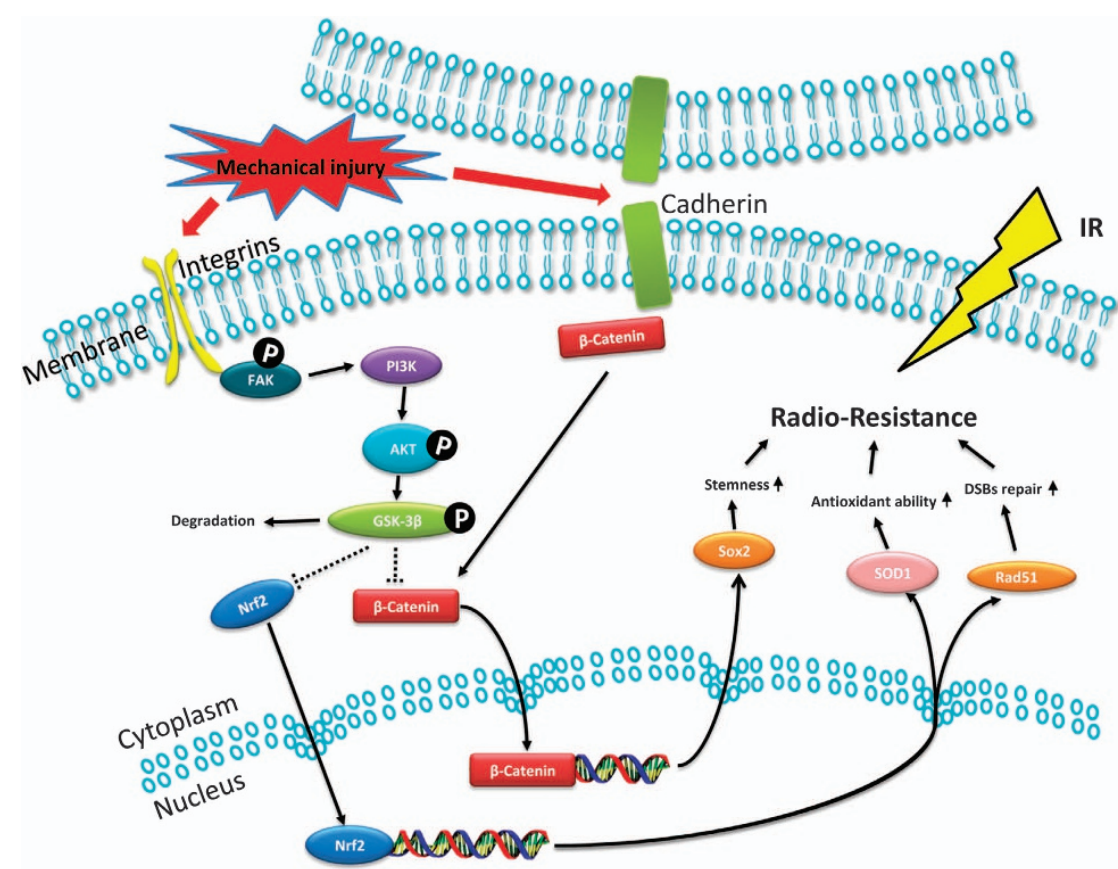

Figure 8 Schematic illustration of mechanical injury-induced increase of radiation resistance in skin fibroblasts. Following mechanical injury, cadherin-cadherin interactions are disrupted, and $\beta$-catenin dissociates from membrane complexes. Focal adhesion complexes mediate mechanotransduction of mechanical injury signals into intracellular

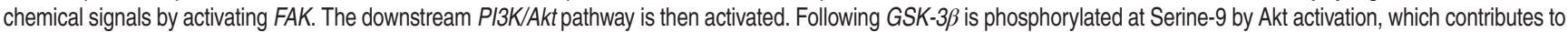

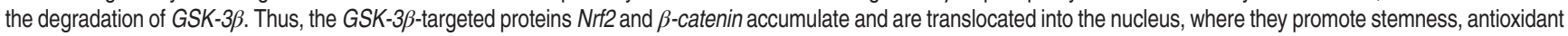
ability, and DSB repair of skin fibroblasts through activation of related genes such as Sox2, SOD1, and Rad51, increasing radioresistance

early steps of differentiation. ${ }^{36}$ However, why stem cells exhibit increased radioresistance remains unclear. According to a study by Mohrin et al., ${ }^{37}$ the resistance of hematopoietic stem cells to the genotoxic stresses of IR was independent of quiescence. Induction of cell proliferation by G-CSF did not decrease their radioresistance and did not enhance susceptibility to acquisition of genetic mutations. Inducing changes in the stemness of cells remains a possible approach to induce radioresistance; however, further studies are needed to clarify the mechanisms underlying this process.

Enhanced antioxidant capability and DNA damage repair is another key consideration for enhancing radioresistance. ${ }^{38}$ Nrf2 is a critical transcriptional factor that controls the expression and coordinated induction of a battery of genes that encode biotransformation reactions, redox homeostasis, energetic metabolism, DNA repair, and proteostasis. ${ }^{39,40}$ The activation of Nrf2 often results from chemical or oxidative stress and causes the dissociation of Nrf2 from Keap1. However, our study is the first to report that mechanical injuries can directly induce upregulation of Nfr2. Nrf2 further regulates the expression of SOD1 in fibroblasts to eliminate the excessive ROS produced directly from ionized water by ionizing particles ${ }^{41}$ or indirectly generated by damaged mitochondria ${ }^{42,43}$ following IR exposure. ${ }^{44,45}$ Other studies have also reported that directly or indirectly upregulated antioxidant proteins protect cells from IR-induced damage. ${ }^{46,47}$ In addition, the increase in Nrf2 expression following mechanical injury increases DNA DSB repair by upregulating Rad51 expression. A recent study has also shown that Nrf2 increases the radioresistance of cancer cells by targeting Rad51 expression in a ROS-independent manner. ${ }^{48}$ According to $\mathrm{Kim}$ et al., ${ }^{49} \mathrm{Nrf2}$ regulates the expression of 53BP1 to protect colonic epithelial cells from ionizing radiation. ${ }^{49}$ In summary, Nrf2 may be another potential mediator for radioresistance by regulating both antioxidant capability and DNA damage repair.

Lastly, the findings in the present study may have important and direct clinical relevance. Adjuvant radiation after surgery is currently a standard of care treatment for multiple cancer types (PMID: 25468225, PMID: 24625455, PMID: 25366825, PMID: 21946673). Although the exact timing of radiotherapy in the postoperative period is debatable, conventional wisdom has dictated that earlier radiotherapy, where tumor volume is maximally low, may maximize its efficacy. On the other hand, insufficient time between initial surgery and radiation is presumed to complicate wound healing related to radiating normal tissues mechanically disrupted by surgery. Importantly, our study demonstrates that mechanical injury may in fact confer radioresistance to normal human skin fibroblasts, while radiosensitizing tumor cells. Our in vitro and in vivo data suggest that the cellular and molecular changes associated with radioresistance may be maximally induced within $72 \mathrm{~h}$ after mechanical injury. These findings raise the possibility that radiation may be administered within days after surgery in the clinical setting and may, furthermore, improve rates of woundhealing complications, compared to the standard timing delay of adjuvant radiotherapy. Likewise, earlier radiotherapy may also capitalize upon the radiosensitizing effects of mechanical injury in tumor tissues and lead to an enhanced reduction of overall tumor burden. Further studies may ultimately 
determine whether these unconventional findings can be translated into changes of clinical practice. In addition, the roles of the enhanced radioresistance and the surviving fibroblasts in wound healing following radiation combined injuries and radiation therapy-associated chronic side effects still needed further study.

\section{Materials and Methods}

Animals. C57/BL mice were obtained from the Center for Experimental Animals at the Third Military Medicine University (TMMU, Chongqing, China). In vivo experiments were conducted in accordance with the Guidelines for the Care and Use of Laboratory Animals of the TMMU, and all procedures were approved by the Animal Care and Use Committee of the TMMU

Combined radiation and skin wound model. To investigate tissue expression of $\gamma \mathrm{H} 2 \mathrm{AX}$, mice in the IR alone group were irradiated at a dose of $6 \mathrm{~Gy}$, and the dorsal skin tissues were obtained at $0.5,2,4,6$, and $12 \mathrm{~h}$ after IR. Circular, full-thickness skin samples $1 \mathrm{~cm}$ in diameter were surgically excised from the middle back of mice in the post-wound IR group. Three days later, the wounded mice were irradiated at a dose of 6 Gy, and the wound tissues were obtained $0.5,2$, 4,6 , and $12 \mathrm{~h}$ after IR. Paraffin sections were stained using rabbit anti- $\gamma \mathrm{H} 2 \mathrm{AX}$ (1:200; \#9718, Cell Signaling, Danvers, MA, USA), and nuclei were co-stained with DAPI (Beyotime, Haimen City, Shanghai, China).

To isolate granulation-derived cells, mice in the pre-wound IR group were irradiated at a dose of $6 \mathrm{~Gy}$, and the skin was wounded immediately after IR. Mice in the postwound IR group were wounded 3 days before 6 Gy radiation. Granulation tissues were harvested from mice in the two groups 10 days after wounding.

Cell isolation and culture. Primary human fibroblasts were obtained after circumcision of foreskins and approval of the protocol by the ethics committee of TMMU. Isolation protocols have been previously described..$^{50}$ In brief, foreskin tissues were cut into $1-2 \mathrm{~cm}^{2}$ pieces after subcutaneous tissue removal and digested for $1 \mathrm{~h}$ at $37^{\circ} \mathrm{C}$ in a digestion medium containing $1 \mathrm{mg} / \mathrm{ml}$ dispase (Roche, Basel, Switzerland). The epidermis was then stripped and digested for another $1 \mathrm{~h}$ at $37^{\circ} \mathrm{C}$ in the digestion medium consisting of DMEM with $0.25 \%$ collagenase I (Worthington Biochemical, Beijing, China). The digested cells were then passed through a $75-\mu \mathrm{m}$ cell strainer, centrifuged, and re-suspended in Iscove's modified Dulbecco's Medium (HyClone, Logan, UT, USA) supplemented with $10 \%$ fetal bovine serum (Gibco, Carlsbad, CA, USA), $100 \mathrm{U} / \mathrm{ml}$ penicillin, and $0.1 \mathrm{mg} / \mathrm{ml}$ streptomycin (all products obtained from Beyotime). Cells were grown to $>90 \%$ confluence, trypsinized (trypsin-EDTA $0.5 \% \mathrm{w} / \mathrm{v}$, Hyclone), and re-plated for experiments.

Mouse granulation tissue cells were isolated as previously described. ${ }^{34}$ Briefly, granulation tissues were harvested 10 days after wounding and cut into $1 \mathrm{~cm}^{2}$ pieces and digested for $1 \mathrm{~h}$ at $37^{\circ} \mathrm{C}$ in a digestion medium containing $0.25 \%$ collagenase I (Worthington Biochemical). The following protocols and culture conditions were the same as those used for human fibroblast isolation and culture. Tumor cell lines (A549 and MG63) were purchased from ATCC (CCL-185 and CRL-1427) and cultured under the same conditions as those for human fibroblasts. LY294002 (50 $\mu \mathrm{M}$; Sigma, St. Louis, MO, USA) and SB216763 (10 $\mu \mathrm{M}$; Sigma) were used to inhibit PI3K and GSK-3 $\beta$, respectively.

Scratching of monolayers. Monolayers of fibroblasts or tumor cells grown to $100 \%$ confluence over a period of $7-14$ days were scratched using a sterile pipette tip. For immunofluorescence experiments, monolayers on chamber slides were scratched once linearly with a $200-\mu l$ pipette tip. For other experiments, monolayers on a six-well plate were scratched with a $1000-\mu$ l pipette tip in an $8 \times 8$ grid pattern; monolayers on $10-\mathrm{cm}$ diameter Petri dishes were scratched with a $1000-\mu l$ pipette tip in a $20 \times 20$ grid pattern. In all cases, non-adherent cells were removed immediately after scratching by changing the culture medium.

Irradiation. Cells were irradiated in an X-ray irradiator (RS2000; Rad Source Technologies, Alpharetta, GA, USA) at room temperature with an absorption rate of $1.284 \mathrm{~Gy} / \mathrm{min}$. A dose of $5 \mathrm{~Gy}$ was administered. Animals received total body irradiation at a dose of 6 Gy.
Statistical analysis. Statistical analyses were performed using the SPSS 13.0 package (SPSS Inc., Chicago, IL, USA). Results were expressed as the mean \pm S.D. An independent-samples t-test was used to determine significant differences between two groups. Comparisons of multiple groups were performed using one-way analysis of variance with corrections for multiple comparisons. $P<0.05$ was considered to be statistically significant.

\section{Conflict of Interest}

The authors declare no conflict of interest.

Acknowledgements. This work was supported by the State Key Basic Research Development Program (2012CB518103), Natural Science Foundation Programs (81372727), Program of New Century Excellent Talents in University (NCET-11-0869) from Ministry of Education and intramural research project grants (BWS13C016, CSTC2013jcyjys10002 and AWS14007-01).

\section{Author contributions}

ZC designed the study, performed experiments, interpreted the data, and wrote the manuscript. XW and TJ were involved in planning experiments and western blots performing. YW, $L T, T D$, and $L W$ participated in planning and performing the animal experiments. CS conceived the study design, experiments plan, and manuscript writing. CSH participated in manuscript writing. ZZ participated in manuscript design and writing. All authors discussed the results and critically reviewed the manuscript.

1. Reid JD, Brooks JW, Ham WT, Evans El. The influence of x-radiation on mortality following thermal flash burns: the site of tissue injury as a factor determining the type of invading bacteria. Ann Surg 1955; 142: 844-850.

2. Ran XZ, Shi CM, Zheng HE, Su YP, Cheng TM. Experimental research on the management of combined radiation-burn injury in China. Radiat Res 2011; 175: 382-389.

3. Mendelsohn FA, Divino CM, Reis ED, Kerstein MD. Wound care after radiation therapy Adv Skin Wound Care 2002; 15: 216-224.

4. Wang J, Boerma M, Fu Q, Hauer-Jensen M. Radiation responses in skin and connective tissues: effect on wound healing and surgical outcome. Hernia 2006; 10: 502-506.

5. Deoliveira D, Jiao Y, Ross JR, Corbin K, Xiao Q, Toncheva G et al. An ear punch model for studying the effect of radiation on wound healing. Int J Radiat Biol 2011; 87: 869-877.

6. Gu Q, Wang D, Cui C, Gao Y, Xia G, Cui X. Effects of radiation on wound healing. J Environ Pathol Toxicol Oncol 1998; 17: 117-123.

7. Shrivastav M, De Haro LP, Nickoloff JA. Regulation of DNA double-strand break repair pathway choice. Cell Res 2008; 18: 134-147.

8. Rogakou EP, Pilch DR, Orr AH, Ivanova VS, Bonner WM. DNA double-stranded breaks induce histone H2AX phosphorylation on serine 139. J Biol Chem 1998; 273: 5858-5868.

9. Keogh MC, Kim JA, Downey M, Fillingham J, Chowdhury D, Harrison JC et al. A phosphatase complex that dephosphorylates gammaH2AX regulates DNA damage checkpoint recovery. Nature 2006; 439: 497-501.

10. Kusch T, Florens L, Macdonald WH, Swanson SK, Glaser RL, Yates JR 3rd et al. Acetylation by Tip60 is required for selective histone variant exchange at DNA lesions. Science 2004; 306: 2084-2087.

11. Eriksson D, Stigbrand T. Radiation-induced cell death mechanisms. Tumour Biol 2010; 31 : 363-372.

12. Coller HA, Sang L, Roberts JM. A new description of cellular quiescence. PLOS Biol 2006; 4: e83.

13. Blanpain C, Mohrin M, Sotiropoulou PA, Passegue E. DNA-damage response in tissuespecific and cancer stem cells. Cell Stem Cell 2011; 8: 16-29.

14. Denis JF, Levesque M, Tran SD, Camarda AJ, Roy S. Axolotl as a model to study scarless wound healing in vertebrates: role of the transforming growth factor beta signaling pathway. Adv Wound Care 2013; 2: 250-260.

15. Finnson KW, Arany PR, Philip A. Transforming growth factor beta signaling in cutaneous wound healing: lessons learned from animal studies. Adv Wound Care 2013; 2: 225-237.

16. Finnson KW, McLean S, Di Guglielmo GM, Philip A. Dynamics of transforming growth factor beta signaling in wound healing and scarring. Adv Wound Care 2013; 2: 195-214.

17. Rustad KC, Wong VW, Gurtner GC. The role of focal adhesion complexes in fibroblast mechanotransduction during scar formation. Differentiation 2013; 86: 87-91.

18. Hytonen VP, Wehrle-Haller B. Mechanosensing in cell-matrix adhesions - converting tension into chemical signals. Exp Cell Res 2015; 343: 35-41.

19. Wong VW, Rustad KC, Akaishi S, Sorkin M, Glotzbach JP, Januszyk M et al. Focal adhesion kinase links mechanical force to skin fibrosis via inflammatory signaling. Nat Med 2012; 18: 148-152.

20. MacLean J, Pasumarthi KB. Signaling mechanisms regulating fibroblast activation, phenoconversion and fibrosis in the heart. Indian J Biochem Biophys 2014: 51: 476-482.

21. Xia H, Nho RS, Kahm J, Kleidon J, Henke CA. Focal adhesion kinase is upstream of phosphatidylinositol 3-kinase/Akt in regulating fibroblast survival in response to contraction 
of type I collagen matrices via a beta 1 integrin viability signaling pathway. J Biol Chem 2004 ; 279: 33024-33034

22. Singh AM, Reynolds D, Cliff T, Ohtsuka S, Mattheyses AL, Sun Y et al. Signaling network crosstalk in human pluripotent cells: a Smad2/3-regulated switch that controls the balance between self-renewal and differentiation. Cell Stem Cell 2012; 10: 312-326.

23. Case N, Ma M, Sen B, Xie Z, Gross TS, Rubin J. Beta-catenin levels influence rapid mechanical responses in osteoblasts. J Biol Chem 2008; 283: 29196-29205.

24. Sen B, Styner M, Xie Z, Case N, Rubin CT, Rubin J. Mechanical loading regulates NFATc1 and beta-catenin signaling through a GSK3beta control node. J Biol Chem 2009; 284: 34607-34617.

25. Hur EM, Zhou FQ. GSK3 signalling in neural development. Nat Rev Neurosci 2010; 11: 539-551.

26. Hoeflich KP, Luo J, Rubie EA, Tsao MS, Jin O, Woodgett JR. Requirement for glycogen synthase kinase-3beta in cell survival and NF-kappaB activation. Nature 2000; 406: 86-90.

27. Cuadrado A. Structural and functional characterization of NRF2 degradation by glycogen synthase kinase 3/beta-TrCP. Free Radic Biol Med 2015; 88(Pt B): 147-157.

28. Clevers H. Wnt/beta-catenin signaling in development and disease. Cell 2006; 127: 469-480.

29. Sekhar KR, Freeman ML. Nrf2 promotes survival following exposure to ionizing radiation. Free Radic Biol Med 2015; 88: 268-274.

30. Yang C, lyer RR, Yu AC, Yong RL, Park DM, Weil RJ et al. beta-Catenin signaling initiates the activation of astrocytes and its dysregulation contributes to the pathogenesis of astrocytomas. Proc Natl Acad Sci USA 2012; 109: 6963-6968.

31. Case N, Thomas J, Sen B, Styner M, Xie Z, Galior K et al. Mechanical regulation of glycogen synthase kinase 3beta (GSK3beta) in mesenchymal stem cells is dependent on Akt protein serine 473 phosphorylation via mTORC2 protein. J Biol Chem 2011; 286: 39450-39456.

32. Nicolay NH, Lopez Perez R, Saffrich R, Huber PE. Radio-resistant mesenchymal stem cells: mechanisms of resistance and potential implications for the clinic. Oncotarget 2015; 6 : 19366-19380.

33. Yang $\mathrm{H}$, Cheng $X P$, Li JW, Yao Q, Ju G. De-differentiation response of cultured astrocytes to injury induced by scratch or conditioned culture medium of scratch-insulted astrocytes. Cell Mol Neurobiol 2009; 29: 455-473

34. Chen Z, Dai T, Chen X, Tan L, Shi C. Activation and regulation of the granulation tissue derived cells with stemness-related properties. Stem Cell Res Ther 2015; 6: 85.

35. Yong RL, Yang C, Lu J, Wang H, Schlaff CD, Tandle A et al. Cell transcriptional state alters genomic patterns of DNA double-strand break repair in human astrocytes. Nat Commun 2014; 5 : 5799

36. Oliver L, Hue E, Sery Q, Lafargue A, Pecqueur C, Paris F et al. Differentiation-related response to DNA breaks in human mesenchymal stem cells. Stem Cells 2013; 31: 800-807.

37. Mohrin M, Bourke E, Alexander D, Warr MR, Barry-Holson K, Le Beau MM et al. Hematopoietic stem cell quiescence promotes error-prone DNA repair and mutagenesis. Cell Stem Cell 2010; 7: 174-185.

38. Sekhar KR, Freeman ML. Nrf2 promotes survival following exposure to ionizing radiation. Free Radic Biol Med 2015; 88(Pt B): 268-274.

39. Niture SK, Khatri R, Jaiswal AK. Regulation of Nrf2-an update. Free Radic Biol Med 2014 66: 36-44.
40. Bryan HK, Olayanju A, Goldring CE, Park BK. The Nrf2 cell defence pathway: Keap1-dependent and -independent mechanisms of regulation. Biochem Pharmacol 2013; 85: 705-717.

41. Collinson E, Dainton FS, Kroh J. Effects of linear energy transfer on the radiolysis of water and heavy water. Nature 1960; 187: 475-477.

42. Gorbunov NV, Kiang JG. Up-regulation of autophagy in small intestine Paneth cells in response to total-body gamma-irradiation. J Pathol 2009; 219: 242-252.

43. Kiang JG, Smith JT, Agravante NG. Geldanamycin analog 17-DMAG inhibits iNOS and caspases in gamma-irradiated human T cells. Radiat Res 2009; 172: 321-330.

44. Dizdaroglu M, Jaruga $P$, Birincioglu $M$, Rodriguez $H$. Free radical-induced damage to DNA: mechanisms and measurement. Free Radic Biol Med 2002; 32: 1102-1115.

45. Kohen R, Nyska A. Oxidation of biological systems: oxidative stress phenomena, antioxidants, redox reactions, and methods for their quantification. Toxicol Pathol 2002; 30: $620-650$.

46. Iglesias-Bartolome R, Patel V, Cotrim A, Leelahavanichkul K, Molinolo AA, Mitchell JB et al. mTOR inhibition prevents epithelial stem cell senescence and protects from radiationinduced mucositis. Cell Stem Cell 2012; 11: 401-414.

47. Gu Q, Feng T, Cao H, Tang Y, Ge X, Luo J et al. HIV-TAT mediated protein transduction of $\mathrm{Cu} / \mathrm{Zn}$-superoxide dismutase-1 (SOD1) protects skin cells from ionizing radiation. Radiat Oncol 2013; 8: 253

48. Jayakumar S, Pal D, Sandur SK. Nrf2 facilitates repair of radiation induced DNA damage through homologous recombination repair pathway in a ROS independent manner in cancer cells. Mutat Res 2015; 779: 33-45.

49. Kim SB, Pandita RK, Eskiocak U, Ly P, Kaisani A, Kumar R et al. Targeting of Nrf2 induces DNA damage signaling and protects colonic epithelial cells from ionizing radiation. Proc Natl Acad Sci USA 2012; 109: E2949-E2955.

50. Gao L, Liu F, Tan L, Liu T, Chen Z, Shi C. The immunosuppressive properties of non-cultured dermal-derived mesenchymal stromal cells and the control of graft-versus-host disease. Biomaterials 2014; 35: 3582-3588

(i) Cell Death and Disease is an open-access journal published by Nature Publishing Group. This work is licensed under a Creative Commons Attribution 4.0 International License. The images or other third party material in this article are included in the article's Creative Commons license, unless indicated otherwise in the credit line; if the material is not included under the Creative Commons license, users will need to obtain permission from the license holder to reproduce the material. To view a copy of this license, visit http://creativecommons.org/licenses/by/4.0/

(C) The Author(s) 2017

Supplementary Information accompanies this paper on Cell Death and Disease website (http://www.nature.com/cddis) 